Check for updates

Cite this: RSC Adv., 2019, 9, 11870

Received 8th March 2019

Accepted 6th April 2019

DOI: 10.1039/c9ra01790a

rsc.li/rsc-advances

\title{
Tough and stretchable inorganic/organic double network ion gel containing gemini-type ionic liquid as a multiple hydrogen bond cross-linker $\dagger$
}

\author{
Tomoki Yasui, Eiji Kamio (iD * and Hideto Matsuyama (D)* \\ Tough and stretchable inorganic/organic double network ion gels containing gemini-type ionic liquids with \\ two $\mathrm{OH}$ groups in the di-cation, which can work as multiple hydrogen bond-based weak cross-linkers of \\ the gel networks, are developed.
}

\section{Introduction}

Ion gels are soft materials having ionic liquid (IL)-based properties and quasi-solid properties. Because of their unique ILbased properties, such as non-volatility, non-flammability, high thermal stability, high ionic conductivity, and high $\mathrm{CO}_{2}$ solubility selectivity, ion gels are suitable for use in electrochemical devices, actuators, and $\mathrm{CO}_{2}$ separation membranes. ${ }^{1-6}$ Such applications also require the ion gel to possess sufficient mechanical strength.

We recently developed tough inorganic/organic composite network ion gels composed of silica particle network clusters and poly( $N, N$-dimethylacrylamide) (PDMAAm) networks, named inorganic/organic micro-double network ( $\mu$-DN) ion gels. $^{7}$ The $\mu$-DN ion gels showed 25 times higher toughness than the PDMAAm based-single network (SN) ion gels. The principal toughening mechanism of the $\mu$-DN ion gels was based on that of the well-known double network hydrogels which are composed of interpenetrating brittle and ductile polymer networks. ${ }^{8}$ In the $\mu$-DN ion gels, the silica particle network cluster acted as the sacrificial bonds and the PDMAAm network with a low cross-link density acted as the hidden length. ${ }^{7,9}$ The excellent toughness of the $\mu$-DN ion gels was attributed to the energy dissipation due to the fracture of the silica particle network clusters during gel deformation. ${ }^{7}$ Therefore, the toughness of the $\mu$-DN ion gels was governed by the amount of the silica particle network clusters which were fractured during deformation. The amount of the fractured silica particle network clusters depends on the fracture strain of the $\mu$-DN ion gels. In fact, our previous study indicated that a decrease in the fracture strain of the inorganic/organic DN ion gels lead to

Center for Membrane and Film Technology, Department of Chemical Science and Engineering, Kobe University, 1-1 Rokkodai-cho, Nada-ku, Kobe, 657-8501, Japan. E-mail: e-kamio@people.kobe-u.ac.jp; matuyama@kobe-u.ac.jp

$\dagger$ Electronic supplementary information (ESI) available: Reaction scheme of gemini-type IL synthesis, ${ }^{1} \mathrm{H}$ NMR data of ILs and TEM image of $\mu$-DN ion gels. See DOI: 10.1039/c9ra01790a a decrease in the toughness. ${ }^{10}$ In addition, because the dissipated energy of the $\mu$-DN ion gels was monotonically increased by increasing the strain up to the fracture point, ${ }^{7}$ it was concluded that many unbroken silica particle network clusters still remained in the fractured $\mu$-DN ion gel. Therefore, it is expected that if the fracture strain of the $\mu$-DN ion gels was increased, more silica particle network clusters would be fractured, which leads to an increase in the toughness of the $\mu-\mathrm{DN}$ ion gels.

A unique and effective method to enhance the fracture strain of the gels, would be to introduce a self-healable crosslink by supplying a large amount of very weak reversible interaction to the gel networks. For example, spider silks show superior extensibility compared to artificial polymeric materials. ${ }^{11,12}$ Spider silk is composed of a semi-amorphous polymer matrix and $\beta$-sheet nanocrystals. ${ }^{11,12}$ The key material of strong spider silk is the well-organized $\beta$-sheet nanocrystals which are connected by weak hydrogen bonds (H-bonds). The H-bond crosslink can be easily reformed during stick-slip deformation. ${ }^{12}$ As a result, the spider silk becomes stretchable and tough. Analogous to the network structures of spider silks, the inorganic/ organic $\mu$-DN ion gel is composed of a polymer network matrix analogous to the semi-amorphous polymer matrix in spider silk, and it has silica nanoparticle clusters corresponding to the $\beta$-sheet nanocrystals in spider silk. Therefore, if the weak interaction can be facilitated between the silica nanoparticle clusters in the $\mu$-DN ion gel, the extensibility and toughness of the ion gel will be improved.

On the other hand, the weak crosslink principle was recently applied to artificial polymeric materials. Song et al. reported polyvinyl alcohol (PVA) cross-linked by melamine. ${ }^{13,14}$ In this system, the melamine molecules acted as the multiple noncovalent cross-linker for PVA via weak H-bonding. Owing to the multiple and simultaneous adsorption and desorption of melamine by the OH group of PVA, the melamine reinforced PVA showed excellent extensibility and toughness; this is due to the destruction and reconstruction of large numbers of $\mathrm{H}$ bonds. In addition, Kean et al. reported the use of metal- 
ligand complex-based cross-linking with rapid dissociation equilibrium to increase the fracture strain of organogels. ${ }^{15}$ The metal-ligand complex supplied weak crosslinking interaction to the polymer network and increased the fracture strain and toughness of the organogels. According to these reports therefore, we can expect the extensibility and toughness of the inorganic/organic $\mu$-DN ion gels to also increase by the introduction of weak interaction-based multiple cross-linking to the polymer network of the $\mu$-DN ion gels.

In this research, we present a non-covalent network bonding strategy using a multiple and weakly cross-linkable agent to increase the fracture strain and toughness of the inorganic/ organic $\mu$-DN ion gels. To this end, H-bonding is useful to form multiple cross-linking points into the network of the ion gels because the $\mathrm{H}$-bonding is easily formed in many kinds of ILs. ${ }^{9,16,17}$ We synthesized gemini-type ILs with two OH groups in each end of the cation (Fig. 1). This was able to act as the multiple H-bond cross-linker of the gel network, to develop tough and stretchable $\mu$-DN ion gels. The synthesized geminiILs; 1,1'-(alkene-1,n-diyl)-bis[3-(2-hydroxyethyl)-imidazolium]di [bis(trifluoromethanesulfonyl)imide] $\left(\left[\mathrm{C}_{n}\left(\mathrm{C}_{2} \mathrm{OHim}\right)_{2}\right]\left[\mathrm{Tf}_{2} \mathrm{~N}\right]_{2}, n\right.$ $=5,7,9,11,12)$, were composed of a hydroxyethyl-imidazoliumbased di-cation and two $\left[\mathrm{Tf}_{2} \mathrm{~N}\right]^{-}$anions (Fig. S1(a-e) $\dagger$ ). The two $\mathrm{OH}$ groups were able to form $\mathrm{H}$-bonds with the dimethylamide group in the PDMAAm network, which acted as the strong $\mathrm{H}_{-}$ bonding acceptor. ${ }^{18,19}$

\section{Experimental}

\section{Materials}

For the synthesis of the gemini-type ILs, 1,5-dibromopentane, 1,7-dibromoheptane, 1,9-dibromononane, 1,11-dibromoundecane, 1,12-dibromododecane, and lithium bis(trifluoromethanesulfonyl)imide $\left(\mathrm{Li}_{[}\left[\mathrm{Tf}_{2} \mathrm{~N}\right]\right)$, all of which were purchased from Tokyo Chemical Industry Co. (Tokyo, Japan), and 1-(2-hydroxyethyl)imidazole and 1-methylimidazole, both of which were purchased from Sigma-Aldrich Co. (St. Louis, $\mathrm{MO}$ ), were used as received. For the preparation of the ion gels, synthesized gemini-type ILs $\left(\left[\mathrm{C}_{n}\left(\mathrm{C}_{2} \mathrm{OHim}\right)_{2}\right]\left[\mathrm{Tf}_{2} \mathrm{~N}\right]_{2}, n=5,7,9\right.$, 11, and 12) and (1,1'-(nonane-1,9-diyl)-bis(3methylimidazolium)di[bis(trifluoromethanesulfonyl)imide]

$\left.\left(\left[\mathrm{C}_{9}(\mathrm{mim})_{2}\right]\left[\mathrm{Tf}_{2} \mathrm{~N}\right]_{2}\right)\right)$, 1-(2-hydroxyethyl)-3-methylimidazolium bis(trifluoromethane-sulfonyl)imide $\left(\left[\mathrm{C}_{2} \mathrm{OHmim}\right]\left[\mathrm{Tf}_{2} \mathrm{~N}\right]\right)$ which was purchased from Tokyo Chemical Industry Co. (Tokyo, Japan), and 1-butyl-3-methylimidazolium bis(trifluoromethanesulfonyl)imide $\left(\left[\mathrm{C}_{4} \mathrm{mim}\right]\left[\mathrm{Tf}_{2} \mathrm{~N}\right]\right)$ which was purchased from Sigma-Aldrich Co. (St. Louis, MO) were used as ILs. These ILs were used after eliminating the dissolved water in them by

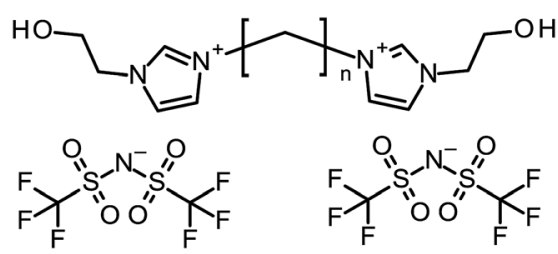

Fig. 1 Chemical structure of gemini-type ILs, $\left[\mathrm{C}_{n}\left(\mathrm{C}_{2} \mathrm{OHim}\right)_{2}\right]\left[\mathrm{Tf}_{2} \mathrm{~N}_{2}\right.$. bubbling dry nitrogen through them for more than $15 \mathrm{~min} . \mathrm{N}, \mathrm{N}$ Dimethylacrylamide (DMAAm) as a monomer of PDMAAm, 2oxoglutaric acid (OA) as a photo-radical initiator, and $N, N^{\prime}$ methylenebis(acrylamide) (MBAA) as a chemical cross-linker of PDMAAm were used to form the organic PDMAAm network in an IL. DMAAm and OA were purchased from Tokyo Chemical Industry Co. (Tokyo, Japan) and used as received. MBAA was purchased from Wako Pure Chemicals Industry Ltd. (Osaka, Japan) and used after purification by recrystallization in ethanol. To form the silica-nanoparticle-based inorganic network, fumed silica nanoparticles (Aerosil 200 with $12 \mathrm{~nm}$ of the primary particle diameter), which were kindly provided by Nippon Aerosil Co. Ltd., were used as received. Ethanol, which was purchased from Wako Pure Chemicals Industry Ltd. (Osaka, Japan), was used as a dispersant of the fumed silica nanoparticles.

\section{Synthesis of gemini-type IL}

The gemini-type ILs $\left[\mathrm{C}_{n}\left(\mathrm{C}_{2} \mathrm{OHim}\right)_{2}\right]\left[\mathrm{Tf}_{2} \mathrm{~N}\right]_{2}$ were synthesized via $\mathrm{S}_{\mathrm{N}} 2$ reaction of $\alpha, \omega$-dibromoalkane and 1-(2-hydroxyethyl) imidazole $\left(\mathrm{C}_{2} \mathrm{OHim}\right)$ followed by metathesis anion exchange processes. ${ }^{20}$ The reaction scheme of synthesis of gemini-type ionic liquids is shown in Scheme S1. $\dagger 1$ molar equivalent of $\alpha, \omega$-dibromoalkane in isopropyl alcohol (IPA) was refluxed with 3 molar equivalents of 1-(2-hydroxyethyl)imidazole for $24 \mathrm{~h}$. After the rotoevaporation of IPA at $313 \mathrm{~K}$, the crude di-bromide salts were dissolved in water and the initial quantity of excess materials were completely extracted with ethyl acetate by repeating the extraction procedure 5 times. After removal of water through rotoevaporation at $333 \mathrm{~K}$, pure di-bromide salts were obtained. 1 molar equivalent of the di-bromide salts was dissolved in water and treated with 2 molar equivalents of the $\mathrm{Li}$ $\left[\mathrm{Tf}_{2} \mathrm{~N}\right]$. The resulting solution was stirred at $298 \mathrm{~K}$ for $24 \mathrm{~h}$. Then, the IL phase was washed by water to remove the generated lithium bromide until all washings were no trace of silver bromide was observed using silver nitrate. The washed ILs were dried at $333 \mathrm{~K}$ in a vacuum oven for $3 \mathrm{~h}$ to remove the remaining water from them, and the gemini-type ILs were obtained. We also synthesized the gemini-type IL without $\mathrm{OH}$ group; $1,1^{\prime}$ (nonane-1,9-diyl)-bis(3-methylimidazolium)di[bis(trifluoromethane-sulfonyl)imide $]\left(\left[\mathrm{C}_{9}(\operatorname{mim})_{2}\right]\left[\mathrm{Tf}_{2} \mathrm{~N}\right]_{2}\right.$, Fig. $\left.\mathrm{S} 1(\mathrm{f}) \dagger\right)$, to confirm the role of the $\mathrm{OH}$ group in the di-cation on the mechanical properties of the ion gels. In addition, non-gemini ILs $\left(\left[\mathrm{C}_{2} \mathrm{OHmim}\right]\left[\mathrm{Tf}_{2} \mathrm{~N}\right]\right.$ and $\left.\left[\mathrm{C}_{4} \mathrm{mim}\right]\left[\mathrm{Tf}_{2} \mathrm{~N}\right]\right)$ were used to confirm the positive effect of the di-cation structure of the ion gels on the mechanical properties. The $\left[\mathrm{C}_{9}(\mathrm{mim})_{2}\right]\left[\mathrm{Tf}_{2} \mathrm{~N}\right]_{2}$ was synthesized in the same manner except that 1-methylimidazole was used instead of $\mathrm{C}_{2} \mathrm{OHim}$. The chemical structures of the synthesized gemini-type ILs were confirmed using ${ }^{1} \mathrm{H}$ NMR measurement (JCZ-400, JEOL RESONANCE Inc., Japan). The results of the ${ }^{1} \mathrm{H}$ NMR measurements were shown in Fig. S1(af) $\cdot \dagger$

\section{Preparation procedure of inorganic/organic $\mu$-DN ion gels}

The inorganic/organic $\mu$-DN ion gels were prepared as reported. ${ }^{7}$ Initially, $0.55 \mathrm{~g}$ of fumed silica nanoparticles were 
added to $9.68 \mathrm{~g}$ of IL/ethanol mixture (ethanol/IL $=0.1 \mathrm{~g} \mathrm{~g}^{-1}$ ). The suspension was vigorously agitated using a vortex mixer and sonicated for $20 \mathrm{~min}$ to disperse the silica nanoparticles in the IL solution. Subsequently, $1.63 \mathrm{~g}$ of DMAAm, $10.2 \mathrm{mg}$ of MBAA (0.4 mol\% on DMAAm basis), and $2.4 \mathrm{mg}$ of OA ( $0.1 \mathrm{~mol} \%$ on DMAAm basis) were added to the suspension and stirred to completely dissolve them in the IL/ethanol mixture. The suspension was injected into a mold consisting of two glass plates with a fluorinated ethylene propylene copolymer (FEP) film and a polytetrafluoroethylene (PTFE) spacer $(1.0 \mathrm{~mm}$ thickness) and was irradiated with $365 \mathrm{~nm}$ UV light for $9 \mathrm{~h}$ to induce the free radical polymerization of DMAAm and MBAA. The obtained ion gel was maintained at $373 \mathrm{~K}$ for $12 \mathrm{~h}$ under a vacuum to remove the unreacted monomer and ethanol. The obtained ion gel was coated with silicon oil (KF96SP, Shin-Etsu Chemical Co., Ltd., Tokyo, Japan) to avoid water absorption and to prevent its adhesion to certain materials. The IL content in the inorganic/organic $\mu$-DN ion gel was adjusted to $c a$. $80 \mathrm{wt} \%$, which was confirmed from the difference in the weight of the dried gels from before and after IL extraction by ethanol.

In addition, PDMAAm SN ion gels were also prepared using the IL/ethanol mixture without silica nanoparticles. The IL content in the PDMAAm SN ion gels was adjusted to $85 \mathrm{wt} \%$; i.e. the content of the PDMAAm network in the PDMAAm SN ion gels was adjusted to be the same as that in the $\mu$-DN ion gels.

\section{Mechanical property measurement}

The mechanical properties of the ion gels were evaluated using an automatic recording universal testing instrument (EZ-LX, Shimadzu Co., Japan) at 298 K. A dumbbell-shaped specimen having a length, width, and thickness of 75.0, 4.0, and $1.0 \mathrm{~mm}$, respectively, was used for the stretching test. Because the inorganic/organic $\mu$-DN ion gels had no volatile component, the mechanical properties could be measured in an open environment without considering any compositional change during the measurement. For all measurements, the sample was attached to the instrument at a distance of $35 \mathrm{~mm}$ between the jigs. A uniaxial stretching test was conducted by stretching the sample at a constant strain rate of $100 \mathrm{~mm} \mathrm{~min}^{-1}$. The fracture stress, fracture strain, and Young's modulus were measured at least three times for each sample. In the cyclic loading-unloading test, the stretching and return operations were performed until the sample broke while incrementally increasing the stretching strain in steps of 1.0.

\section{Transmission electron microscope (TEM) observation}

The silica particle-based inorganic network in the inorganic/ organic $\mu$-DN ion gel was observed using a field-emission transmission electron microscope (FE-TEM) (JEM-2100F, JEOL Ltd., Japan). A cubic sample of the ion gel with size $1 \mathrm{~mm}$ was immersed in a sufficient volume of ethanol for $12 \mathrm{~h}$ to exchange the IL in the sample for ethanol. The sample was immersed in a precursor solution of epoxy resin (Plain Resin Kit, Nisshin EM Co., Ltd.)/ethanol mixture (weight ratio of $1 \mathrm{~g} \mathrm{~g}^{-1}$ ) for $6 \mathrm{~h}$ and then immersed in a precursor solution of epoxy resin for $12 \mathrm{~h}$ to completely exchange the ethanol in the sample with the precursor. The sample in the precursor was poured into a silicon mold and cured at a temperature of $343 \mathrm{~K}$ for 5 days. The resin block embedding the gel sample was then thinsectioned using an ultramicrotome (UC7, Leica Microsystems $\mathrm{GmbH}$, Germany), and sections of $100 \mathrm{~nm}$ thickness were collected on a copper mesh TEM grid with a carbon support film and observed by the FE-TEM. The acceleration voltage of the electron gun used for observation was $200 \mathrm{kV}$.

\section{Fourier-transform infrared spectroscopy (FT-IR) measurement}

FT-IR spectra (Nicolet iS5vFT-IR; Thermo Scientific Inc.) of the ILs and ion gels were measured to confirm the H-bond formation between IL and PDMAAm. The attenuated total reflection (ATR) method was used for the FT-IR measurement. For the semi-quantitative analysis, the FT-IR spectra were normalized by absorbance at $1564 \mathrm{~cm}^{-1}$ which was attributed to the $\mathrm{C}=\mathrm{N}$ stretching vibration.

\section{Adsorption isotherm of $\left[\mathrm{C}_{9}\left(\mathrm{C}_{2} \mathrm{OHim}\right)_{2}\right]\left[\mathrm{Tf}_{2} \mathrm{~N}\right]_{2}$ on silica particle}

The adsorption isotherm of $\left[\mathrm{C}_{9}\left(\mathrm{C}_{2} \mathrm{OHim}\right)_{2}\right]\left[\mathrm{Tf}_{2} \mathrm{~N}\right]_{2}$ on the silica particle in $\left[\mathrm{C}_{4} \mathrm{mim}\right]\left[\mathrm{Tf}_{2} \mathrm{~N}\right]$ used as the solvent was measured to confirm the adsorption of $\left[\mathrm{C}_{9}\left(\mathrm{C}_{2} \mathrm{OHim}\right)_{2}\right]\left[\mathrm{Tf}_{2} \mathrm{~N}\right]_{2}$ on the silica particle via $\left[\mathrm{C}_{9}\left(\mathrm{C}_{2} \mathrm{OHim}\right)_{2}\right]$ di-cation. $0.1 \mathrm{~g}$ of the silica particles with $75 \mu \mathrm{m}$ of its diameter (Silica Gel 60, spherical neutrality purchased from NACALAI TESQUE, INC., Kyoto, Japan) were added to the $1.0 \mathrm{~g}$ of $\left[\mathrm{C}_{9}\left(\mathrm{C}_{2} \mathrm{OHim}\right)_{2}\right]\left[\mathrm{Tf}_{2} \mathrm{~N}\right]_{2} /\left[\mathrm{C}_{4} \mathrm{mim}\right]\left[\mathrm{Tf}_{2} \mathrm{~N}\right]$ solution with various ratios. In this experiment, the $\mu \mathrm{m}$-sized silica particles were used to achieve a complete separation of the IL mixture and the silica particles. The mixture was stirred at $298 \mathrm{~K}$ for $6 \mathrm{~h}$. After the removal of the silica particles by decantation, the $\left[\mathrm{C}_{9}\left(\mathrm{C}_{2} \mathrm{OHim}\right)_{2}\right]\left[\mathrm{Tf}_{2} \mathrm{~N}\right]_{2} /\left[\mathrm{C}_{4} \mathrm{mim}\right]\left[\mathrm{Tf}_{2} \mathrm{~N}\right]$ ratio of the supernatant IL mixtures were measured by ${ }^{1} \mathrm{H}$ NMR. It was confirmed that the adsorption equilibrium could be reached in less than $6 \mathrm{~h}$. The adsorption amount was calculated from the difference in the $\left[\mathrm{C}_{9}\left(\mathrm{C}_{2} \mathrm{OHim}\right)_{2}\right]\left[\mathrm{Tf}_{2} \mathrm{~N}\right]_{2}$ concentration before the addition of silica particles, and the concentration after adsorption equilibration. In the calculation, it was assumed that the volume of $\left[\mathrm{C}_{9}\left(\mathrm{C}_{2} \mathrm{OHim}\right)_{2}\right]\left[\mathrm{Tf}_{2} \mathrm{~N}\right]_{2} /\left[\mathrm{C}_{4} \mathrm{mim}\right]\left[\mathrm{Tf}_{2} \mathrm{~N}\right]$ mixture was constant, and that $\left[\mathrm{C}_{4} \mathrm{mim}\right]\left[\mathrm{Tf}_{2} \mathrm{~N}\right]$ did not get adsorbed on the silica particle. The $\left[\mathrm{C}_{9}\left(\mathrm{C}_{2} \mathrm{OHim}\right)_{2}\right]\left[\mathrm{Tf}_{2} \mathrm{~N}\right]_{2}$ concentration was calculated by the $\left[\mathrm{C}_{9}\left(\mathrm{C}_{2} \mathrm{OHim}\right)_{2}\right]\left[\mathrm{Tf}_{2} \mathrm{~N}\right]_{2} /\left[\mathrm{C}_{4} \mathrm{mim}\right]\left[\mathrm{Tf}_{2} \mathrm{~N}\right]$ ratio which was determined from the integral ratio of $\mathrm{CH}_{2}-\mathrm{OH}$ in $\left[\mathrm{C}_{9}\left(\mathrm{C}_{2} \mathrm{OHim}\right)_{2}\right]\left[\mathrm{Tf}_{2} \mathrm{~N}\right]_{2}$ and $\mathrm{CH}_{3}-\mathrm{CH}_{2}$ in $\left[\mathrm{C}_{4} \mathrm{mim}\right]\left[\mathrm{Tf}_{2} \mathrm{~N}\right]$ as determined by the ${ }^{1} \mathrm{H}$ NMR measurement.

\section{Results and discussion}

Mechanical properties of the inorganic/organic $\mu$-DN ion gels containing gemini-type ILs

The mechanical properties of the $\mu$-DN ion gels are shown in Fig. 2. Owing to the energy dissipation mechanism based on the internal rupture of the inorganic network clusters, the fracture stress of the $\mu$-DN ion gels was much higher than those of the PDMAAm SN ion gels (Fig. 2(a)). Among the $\mu$-DN ion gels, it is 
(a)

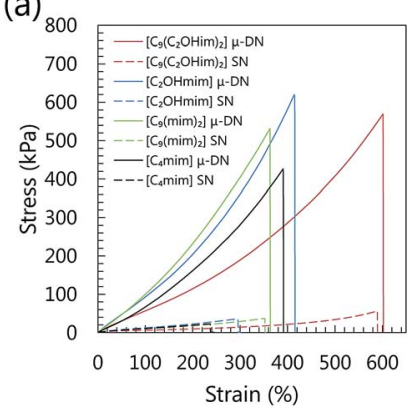

(b)
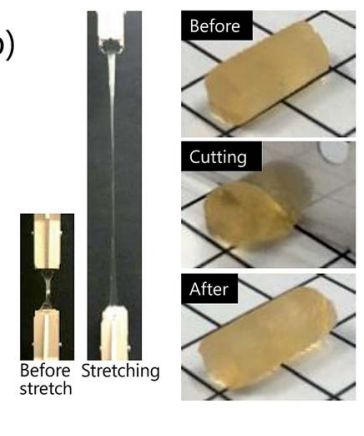

Fig. 2 Mechanical properties of ion gels. (a) Stress-strain curves of the $\mu$-DN ion gels and PDMAAm-based SN ion gels containing various types of ILs. (b) Stretching and cutting states of the $\mu$-DN ion gel containing $\left[\mathrm{C}_{9}\left(\mathrm{C}_{2} \mathrm{OHim}\right)_{2}\right]\left[\mathrm{Tf}_{2} \mathrm{~N}\right]_{2}$. The IL content of the ion gels were ca. $80 \mathrm{wt} \%$.

noteworthy that the gemini-type $\left[\mathrm{C}_{9}\left(\mathrm{C}_{2} \mathrm{OHim}\right)_{2}\right]\left[\mathrm{Tf}_{2} \mathrm{~N}\right]_{2}$-based $\mu$ DN ion gel had outstanding mechanical strength. The toughness of the $\left[\mathrm{C}_{9}\left(\mathrm{C}_{2} \mathrm{OHim}\right)_{2}\right]\left[\mathrm{Tf}_{2} \mathrm{~N}\right]_{2}$-based $\mu$-DN ion gel $(1330 \mathrm{~kJ}$ $\mathrm{m}^{-3}$ ) was almost double of that of the non-gemini-type $\left[\mathrm{C}_{4} \mathrm{mim}\right]$ $\left[\mathrm{Tf}_{2} \mathrm{~N}\right]$-based $\mu$-DN ion gel $\left(680 \mathrm{~kJ} \mathrm{~m}^{-3}\right)$. The excellent stretchability and toughness of the $\mu$-DN ion gel containing $80 \mathrm{wt} \%$ of $\left[\mathrm{C}_{9}\left(\mathrm{C}_{2} \mathrm{OHim}\right)_{2}\right]\left[\mathrm{Tf}_{2} \mathrm{~N}\right]_{2}$ are demonstrated in Fig. $2(\mathrm{~b})$. The $\mu$-DN ion gel could be extended to 6 times the original length and could not be cut by pushing with a sharp blade. As shown in Fig. 3(a), the $\left[\mathrm{C}_{9}\left(\mathrm{C}_{2} \mathrm{OHim}\right)_{2}\right]\left[\mathrm{Tf}_{2} \mathrm{~N}\right]_{2}$-based $\mu$-DN ion gel showed clear hysteresis during the cyclic tensile stress loadingunloading test. In addition, the silica particle network clusters were observed in the TEM image (Fig. S2 $\dagger$ ) that were also formed in the $\left[\mathrm{C}_{4} \mathrm{mim}\right]\left[\mathrm{Tf}_{2} \mathrm{~N}\right]$-based $\mu$-DN ion gel as reported previously. ${ }^{7}$ These results clearly demonstrated that the principal toughening mechanism of the $\left[\mathrm{C}_{9}\left(\mathrm{C}_{2} \mathrm{OHim}\right)_{2}\right]\left[\mathrm{Tf}_{2} \mathrm{~N}\right]_{2^{-}}$ based $\mu$-DN ion gel was based on the energy dissipation mechanism (Fig. 3(b-d)). Therefore, to realize outstanding mechanism. However, the other $\mu$-DN ion gels also enhanced their mechanical strength based on the energy dissipation extensibility and toughness, another toughening mechanism, which would be realized by the introduction of weak $\mathrm{H}$-bonding interaction based on the multiple and simultaneous adsorption and desorption of $\left[\mathrm{C}_{9}\left(\mathrm{C}_{2} \mathrm{OHim}\right)_{2}\right]\left[\mathrm{Tf}_{2} \mathrm{~N}\right]_{2}$ to the inorganic and organic networks, could be incorporated into the $\left[\mathrm{C}_{9}\left(\mathrm{C}_{2} \mathrm{OHim}\right)_{2}\right]$ $\left[\mathrm{Tf}_{2} \mathrm{~N}\right]_{2}$-based $\mu$-DN ion gel. According to our design criteria of the gemini-type ILs with $\mathrm{OH}$ groups, the two $\mathrm{OH}$ groups in the di-cation could form $\mathrm{H}$-bonds with the $\mathrm{OH}$ group on the silica nanoparticles and $\mathrm{C}=\mathrm{O}$ group in the PDMAAm networks. If the $\mathrm{OH}$ groups can adsorb the silica nanoparticles, the silica particle network cluster will be cross-linked by large numbers of the di-cation via H-bonding. In the same way, the di-cation could also cross-link the PDMAAm networks via H-bonds. Thus, large numbers of weak crosslinks could allow the ion gel to become highly stretchable and tough. To confirm the role of the gemini-type IL with OH groups as a weak cross-linker between the gel networks via $\mathrm{H}$-bonding, we examined the $\mathrm{H}$ bonding ability of the IL to the silica particles and PDMAAm. (a) $\left[\mathrm{C}_{9}\left(\mathrm{C}_{2} \mathrm{OHim}\right)_{2}\right]\left[\mathrm{Tf}_{2} \mathrm{~N}\right]_{2}$

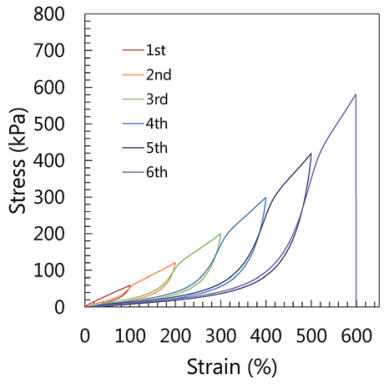

(c) $\left[\mathrm{C}_{2} \mathrm{OHmim}\right]\left[\mathrm{Tf}_{2} \mathrm{~N}\right]$

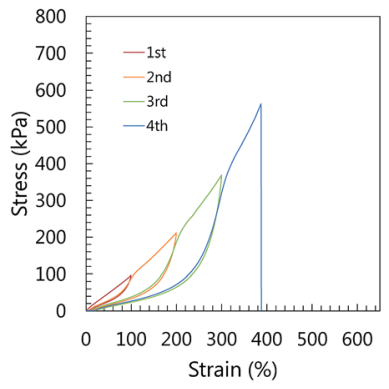

(b) $\left[\mathrm{C}_{9}(\mathrm{mim})_{2}\right]\left[\mathrm{Tf}_{2} \mathrm{~N}\right]_{2}$

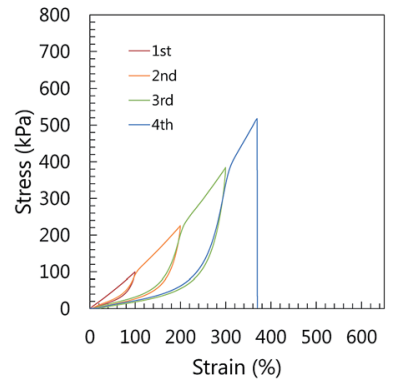

(d) $\left[\mathrm{C}_{4} \operatorname{mim}\right]\left[\mathrm{Tf}_{2} \mathrm{~N}\right]$

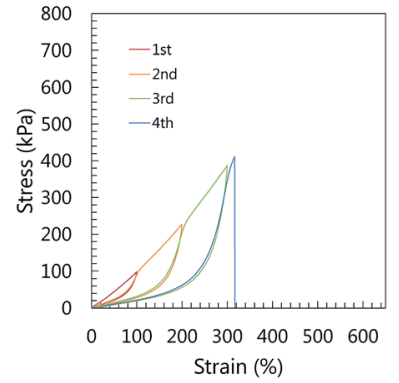

Fig. 3 Cyclic loading-unloading curves of inorganic/organic $\mu$-DN ion gels containing (a) $\left[\mathrm{C}_{9}\left(\mathrm{C}_{2} \mathrm{OHim}\right)_{2}\right]\left[\mathrm{Tf}_{2} \mathrm{~N}\right]_{2}$, (b) $\left[\mathrm{C}_{9}(\mathrm{mim})_{2}\right]\left[\mathrm{Tf}_{2} \mathrm{~N}\right]_{2}$, (c) $\left[\mathrm{C}_{2} \mathrm{OHmim}\right]\left[\mathrm{Tf}_{2} \mathrm{~N}\right]$, and (d) $\left[\mathrm{C}_{4} \operatorname{mim}\right]\left[\mathrm{Tf}_{2} \mathrm{~N}\right]$.

\section{Adsorption ability of the gemini-type IL having $\mathrm{OH}$ groups on the silica particle surface}

Initially, we confirmed the adsorption ability of the gemini-type IL having $\mathrm{OH}$ groups on the silica particle surface. The adsorption isotherm of $\left[\mathrm{C}_{9}\left(\mathrm{C}_{2} \mathrm{OHim}\right)_{2}\right]\left[\mathrm{Tf}_{2} \mathrm{~N}\right]_{2}$ on silica particles is shown in Fig. 4. In this experiment, $\left[\mathrm{C}_{4} \mathrm{mim}\right]\left[\mathrm{Tf}_{2} \mathrm{~N}\right]$ was used as the solvent and silica particles having a diameter of $75 \mu \mathrm{m}$ were used to achieve a complete separation of the IL mixture and the silica particles. Because the silica particle used in the adsorption test was not the same as that used to prepare the $\mu$ DN ion gels, the absorption amount of IL shown in Fig. 4 is different from that of the fumed silica nanoparticles used in the preparation of the $\mu$-DN ion gels. However, the adsorption ability of the IL to the silanol groups on silica particles can be

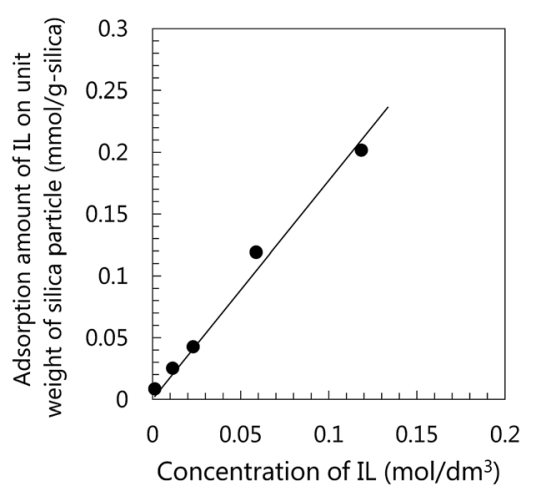

Fig. 4 Adsorption isotherm of $\left[\mathrm{C}_{9}\left(\mathrm{C}_{2} \mathrm{OHim}\right)_{2}\right]\left[T f_{2} \mathrm{~N}\right]_{2}$ on silica particle in $\left[\mathrm{C}_{4} \mathrm{mim}\right]\left[\mathrm{Tf}_{2} \mathrm{~N}\right]$. 
evaluated using the $\mu \mathrm{m}$-sized silica particles. As shown in Fig. 4, it can be clearly concluded that the IL can adsorb on the surface of the silica particles via the weak H-bonding between the silanol group of the silica particles and the $\mathrm{OH}$ groups of the IL.

\section{Interaction of the gemini-type $\mathrm{IL}$ having $\mathrm{OH}$ groups with PDMAAm network}

To confirm the H-bonding ability of the synthesized gemini-type ILs with $\mathrm{OH}$ groups with the PDMAAm network in the $\mu$-DN ion gel, the interaction between $\left[\mathrm{C}_{9}\left(\mathrm{C}_{2} \mathrm{OHim}\right)_{2}\right]\left[\mathrm{Tf}_{2} \mathrm{~N}\right]_{2}$ and the PDMAAm network was evaluated from the FT-IR measurement. The results of the FT-IR measurement are shown in Fig. 5. Fig. 5(a) shows the FT-IR spectra of the PDMAAm SN ion gels containing various ILs. In the cases of the ion gels containing $\left[\mathrm{C}_{4} \mathrm{mim}\right]\left[\mathrm{Tf}_{2} \mathrm{~N}\right]$ and $\left[\mathrm{C}_{9}(\mathrm{mim})_{2}\right]\left[\mathrm{Tf}_{2} \mathrm{~N}\right]_{2}$, the absorbance peak attributed to the stretching vibration of the $\mathrm{C}=\mathrm{O}$ group of PDMAAm appeared at $1630 \mathrm{~cm}^{-1}$. On the other hand, in the cases of the $\left[\mathrm{C}_{9}\left(\mathrm{C}_{2} \mathrm{OHim}\right)_{2}\right]\left[\mathrm{Tf}_{2} \mathrm{~N}\right]_{2}$ and $\left[\mathrm{C}_{2} \mathrm{OHmim}\right]\left[\mathrm{Tf}_{2} \mathrm{~N}\right]$, which had the $\mathrm{OH}$ group in the cation, the stretching vibration peak of the $\mathrm{C}=\mathrm{O}$ group appeared at $1625 \mathrm{~cm}^{-1}$, which was a slightly lower wavenumber than that of the $\left[\mathrm{C}_{4} \mathrm{mim}\right]\left[\mathrm{Tf}_{2} \mathrm{~N}\right]$ and $\left[\mathrm{C}_{9}(\mathrm{mim})_{2}\right]\left[\mathrm{Tf}_{2} \mathrm{~N}\right]_{2}$-based PDMAAm SN ion gels. This red shift indicated that the $\mathrm{C}=\mathrm{O}$ group in the PDMAAm networks formed $\mathrm{H}$-bonds with the $\mathrm{OH}$ group in $\left[\mathrm{C}_{9}\left(\mathrm{C}_{2} \mathrm{OHim}\right)_{2}\right]\left[\mathrm{Tf}_{2} \mathrm{~N}\right]_{2}$ and $\left[\mathrm{C}_{2} \mathrm{OHmim}\right]\left[\mathrm{Tf}_{2} \mathrm{~N}\right]$. The same results were obtained for the inorganic/organic $\mu$-DN ion gels as shown in Fig. 5(b).

The formation of the $\mathrm{H}$-bonds between the $\mathrm{OH}$ group and $\mathrm{C}=\mathrm{O}$ group was also confirmed by the absorbance peak shift of the stretching vibration of the $\mathrm{OH}$ group in the IL molecules. As shown in Fig. 6 , the FT-IR spectrum of the neat $\left[\mathrm{C}_{9}\left(\mathrm{C}_{2} \mathrm{OHim}\right)_{2}\right]$ $\left[\mathrm{Tf}_{2} \mathrm{~N}\right]_{2}$ showed an absorbance peak at $3536 \mathrm{~cm}^{-1}$, which was attributed to the stretching vibration of the $\mathrm{OH}$ group forming an $\mathrm{H}$-bond with the $\left[\mathrm{Tf}_{2} \mathrm{~N}\right]^{-}$anion. ${ }^{21}$ For the $\left[\mathrm{C}_{9}\left(\mathrm{C}_{2} \mathrm{OHim}\right)_{2}\right]$ $\left[\mathrm{Tf}_{2} \mathrm{~N}\right]_{2}$-based $\mu$-DN and PDMAAm $\mathrm{SN}$ ion gels, a new absorbance peak was appeared around $3400 \mathrm{~cm}^{-1}$. However, in the case of the silica SN ion gel, no additional peak was visible at $3400 \mathrm{~cm}^{-1}$. The new peak was attributed to the stretching vibration of the $\mathrm{OH}$ groups in the IL molecule that formed an $\mathrm{H}$ bond with the $\mathrm{C}=\mathrm{O}$ group in the PDMAAm network. To clarify the formation of the $\mathrm{H}$-bond between the $\left[\mathrm{C}_{9}\left(\mathrm{C}_{2} \mathrm{OHim}\right)_{2}\right]$ dication and PDMAAm semi-quantitatively, the FT-IR spectra (a) PDMAAm SN ion gels

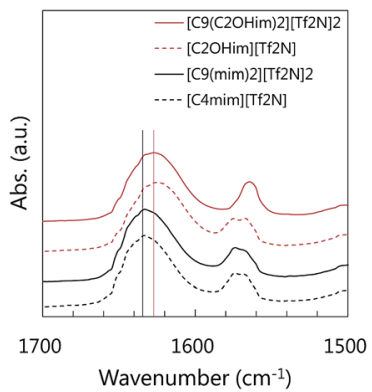

(b) $\mu$-DN ion gels

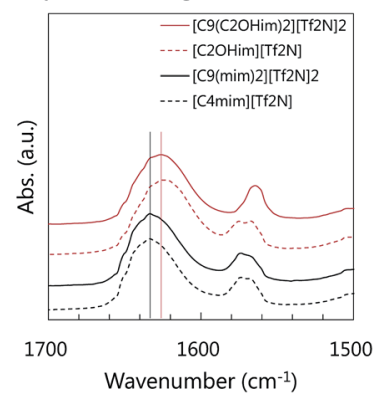

Fig. 5 FT-IR spectra of ion gels containing various types of ILs. (a) PDMAAm SN ion gels. (b) $\mu$-DN ion gels.

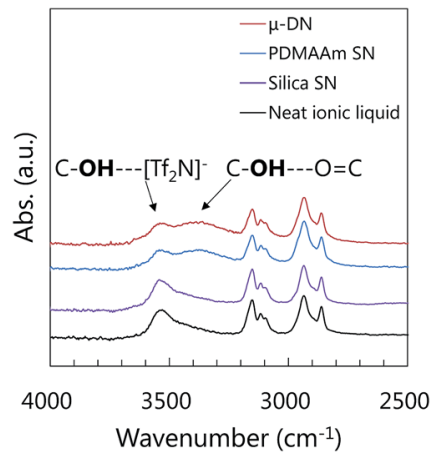

Fig. 6 FT-IR spectra of $\mu$-DN, PDMAAm-based SN, and silica particle network-based $\mathrm{SN}$ ion gels containing $\left[\mathrm{C}_{9}\left(\mathrm{C}_{2} \mathrm{OHim}\right)_{2}\right]\left[\mathrm{Tf}_{2} \mathrm{~N}\right]_{2}$.

were normalized by the absorbance at $1564 \mathrm{~cm}^{-1}$ which was attributed to the $\mathrm{C}=\mathrm{N}$ stretching vibration in the imidazolium ring of the IL. The peak separation results of the normalized FTIR spectra are shown in Fig. 7. In the FT-IR spectrum of the neat $\left[\mathrm{C}_{9}\left(\mathrm{C}_{2} \mathrm{OHim}\right)_{2}\right]\left[\mathrm{Tf}_{2} \mathrm{~N}\right]_{2}$ shown in Fig. $7(\mathrm{a})$, the absorbance peak attributed to the stretching vibration of the $\mathrm{OH}$ group can be separated into $3536 \mathrm{~cm}^{-1}$ and $3438 \mathrm{~cm}^{-1}$. The former was attributed to the $\mathrm{OH}$ group which underwent $\mathrm{H}$-bonding with the $\left[\mathrm{Tf}_{2} \mathrm{~N}\right]^{-}$anion and the latter was attributed to the $\mathrm{OH}$ group which completed $\mathrm{H}$-bonding with the $\mathrm{OH}$ group of another IL molecule. ${ }^{21}$ On the other hand, as shown in Fig. 7(b), in the case of $\left[\mathrm{C}_{9}\left(\mathrm{C}_{2} \mathrm{OHim}\right)_{2}\right]\left[\mathrm{Tf}_{2} \mathrm{~N}\right]_{2}$-based PDMAAm $\mathrm{SN}$ ion gel, the absorbance at $3536 \mathrm{~cm}^{-1}$ became ca. $60 \%$ of that of neat $\left[\mathrm{C}_{9}\left(\mathrm{C}_{2} \mathrm{OHim}\right)_{2}\right]\left[\mathrm{Tf}_{2} \mathrm{~N}\right]_{2}$. This result indicated that the $\mathrm{OH}$ group which formed an $\mathrm{H}$-bond with $\left[\mathrm{Tf}_{2} \mathrm{~N}\right]^{-}$anion in the neat IL were switched to form another H-bond in the PDMAAm SN ion gel. On the other hand, the absorbance peak at $3438 \mathrm{~cm}^{-1}$ of neat $\left[\mathrm{C}_{9}\left(\mathrm{C}_{2} \mathrm{OHim}\right)_{2}\right]\left[\mathrm{Tf}_{2} \mathrm{~N}\right]_{2}$ was shifted to $3380 \mathrm{~cm}^{-1}$ and became large in the PDMAAm SN ion gel. This result suggested that the absorption peak at $3380 \mathrm{~cm}^{-1}$ in the PDMAAm SN ion gel was the sum of the stretching vibration of the $\mathrm{OH}$ groups which formed $\mathrm{H}$-bonds with the $\mathrm{OH}$ group of another IL molecule and with the $\mathrm{C}=\mathrm{O}$ group in PDMAAm. Because the $\mathrm{C}=\mathrm{O}$ group has strong H-bond basicity, it could form strong $\mathrm{H}$-bonds with the $\mathrm{OH}$ group. From these results, it was confirmed that
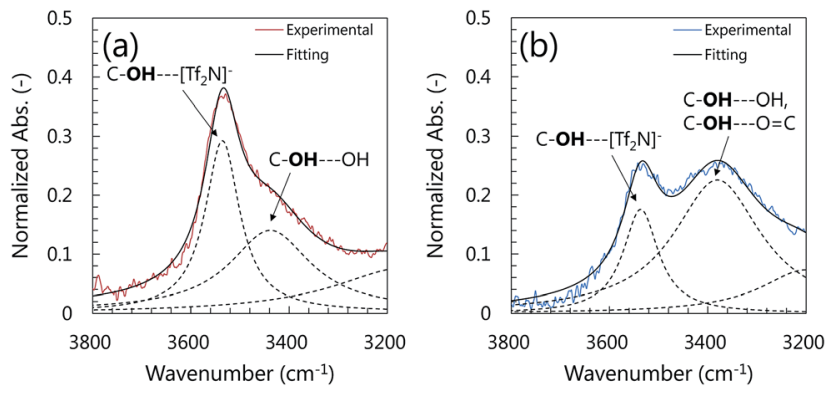

Fig. 7 Normalized absorbance of neat $\left[\mathrm{C}_{9}\left(\mathrm{C}_{2} \mathrm{OHim}\right)_{2}\right]\left[\mathrm{Tf}_{2} \mathrm{~N}\right]_{2}(\mathrm{a})$ and PDMAAm-based SN ion gel containing $\left[\mathrm{C}_{9}\left(\mathrm{C}_{2} \mathrm{OHim}\right)_{2}\right]\left[\mathrm{Tf}_{2} \mathrm{~N}\right]_{2}$ (b). The absorbance was normalized by that at $1564 \mathrm{~cm}^{-1}$ for $\mathrm{C}=\mathrm{N}$ stretching vibration 
$\left[\mathrm{C}_{9}\left(\mathrm{C}_{2} \mathrm{OHim}\right)_{2}\right]\left[\mathrm{Tf}_{2} \mathrm{~N}\right]_{2}$ could interact with the PDMAAm network.

\section{Toughening mechanism of the $\mu$-DN ion gel containing $\left[\mathrm{C}_{n}\left(\mathrm{C}_{2} \mathrm{OHim}\right)_{2}\right]\left[\mathrm{Tf}_{2} \mathrm{~N}\right]_{2}$}

From the above mentioned results, it was confirmed that the synthesized gemini-type ILs with OH groups were able to adsorb to silica nanoparticles and interact with the PDMAAm network. Therefore, it can be expected that the ion gels containing the gemini-type ILs with $\mathrm{OH}$ groups should have high extensibility. To confirm the role of the gemini-type ILs with $\mathrm{OH}$ groups for the enhancement of the extensibility of the ion gels, the mechanical properties, especially the extensibility, of the ion gels are again reviewed in detail. As clearly shown in Fig. 2(a), the fracture strains of the $\mu$-DN ion gels containing $\left[\mathrm{C}_{2} \mathrm{OHim}\right]$ $\left[\mathrm{Tf}_{2} \mathrm{~N}\right]$ and $\left[\mathrm{C}_{9}(\mathrm{mim})_{2}\right]\left[\mathrm{Tf}_{2} \mathrm{~N}\right]$ were almost the same as those of the ion gels with $\left[\mathrm{C}_{4} \mathrm{mim}\right]\left[\mathrm{Tf}_{2} \mathrm{~N}\right]$. Because $\left[\mathrm{C}_{2} \mathrm{OHim}\right]\left[\mathrm{Tf}_{2} \mathrm{~N}\right]$ has only one $\mathrm{OH}$ group in the molecule, it could not be used as a cross-linker. In addition, because the gemini-type $\left[\mathrm{C}_{9}(\mathrm{mim})_{2}\right]$ $\left[\mathrm{Tf}_{2} \mathrm{~N}\right]$ has no $\mathrm{OH}$ group, it could be hardly adsorbed on the silica nanoparticle and interacted with the PDMAAm chain. As a result, these ILs could not improve the extensibility of the ion gels. On the other hand, the fracture strains of the $\mathrm{SN}$ as well as the $\mu$-DN ion gels containing $\left[\mathrm{C}_{9}\left(\mathrm{C}_{2} \mathrm{OHim}\right)_{2}\right]\left[\mathrm{Tf}_{2} \mathrm{~N}\right]_{2}$ were much higher than those of the other ion gels. In addition, as indicated in Fig. 8(a), all of the $\mu$-DN ion gels with $\left[\mathrm{C}_{n}\left(\mathrm{C}_{2} \mathrm{OHim}\right)_{2}\right]\left[\mathrm{Tf}_{2} \mathrm{~N}\right]_{2}$ had similar extensibility. These results indicated that the gemini-type ILs with OH groups crosslinked the gel networks and increased the extensibility of the $\mu$-DN ion gels.

Owing to the multiple and simultaneous adsorption and desorption of the $\mathrm{OH}$ groups of the $\left[\mathrm{C}_{n}\left(\mathrm{C}_{2} \mathrm{OHim}\right)_{2}\right]\left[\mathrm{Tf}_{2} \mathrm{~N}\right]_{2}$, the ion gels had excellent extensibility compared to the ion gels with the other ILs. However, the effect of the cross-linking of silica particles by the $\left[\mathrm{C}_{9}\left(\mathrm{C}_{2} \mathrm{OHim}\right)_{2}\right]\left[\mathrm{Tf}_{2} \mathrm{~N}\right]_{2}$ could be considered insufficient because the fracture strains of the $\mu$-DN ion gel and the PDMAAm-based SN ion gel without silica particle network clusters were almost the same, as indicated in Fig. 8(a). This means the main factor in the enhancement of the extensibility of the $\left[\mathrm{C}_{n}\left(\mathrm{C}_{2} \mathrm{OHim}\right)_{2}\right]\left[\mathrm{Tf}_{2} \mathrm{~N}\right]_{2}$-based ion gels was the weak crosslinking of the PDMAAm networks by the ILs. Because the silica particles were spherical in shape and the contact area between them was smaller than that between the $\beta$-sheet nanocrystals in
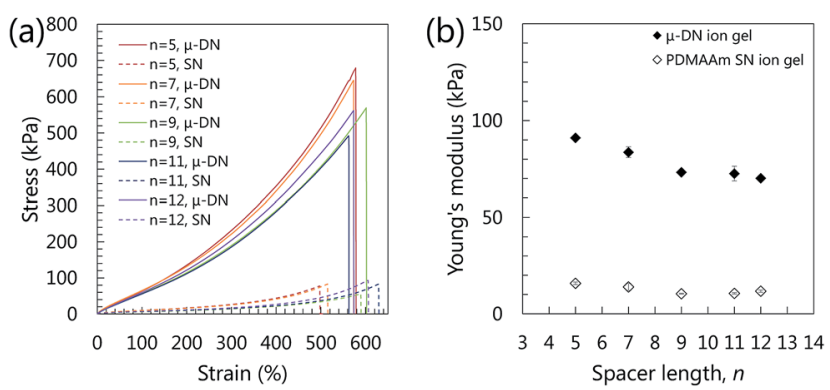

Fig. 8 Stress-strain curves (a) and Young's moduli (b) of the $\mu$-DN ion gel containing $\left[\mathrm{C}_{n}\left(\mathrm{C}_{2} \mathrm{OHim}\right)_{2}\right]\left[\mathrm{Tf}_{2} \mathrm{~N}\right]_{2}$ with several spacer length, $n$. The IL content of the ion gels were ca. $80 \mathrm{wt} \%$. spider silk, the cross-linking between the silica nanoparticles in the $\mu$-DN ion gels could not work to enhance the extensibility enough.

On the other hand, the effect of the cross-linking between the silica nanoparticles in the ion gels by $\left[\mathrm{C}_{n}\left(\mathrm{C}_{2} \mathrm{OHim}\right)_{2}\right]\left[\mathrm{Tf}_{2} \mathrm{~N}\right]_{2}$ was apparent in their Young's moduli. As shown in Fig. 8(b), the Young's modulus of the $\mu$-DN ion gels containing $\left[\mathrm{C}_{n}\left(\mathrm{C}_{2^{-}}\right.\right.$ OHim $\left.)_{2}\right]\left[\mathrm{Tf}_{2} \mathrm{~N}\right]_{2}$ increased with decreasing the spacer length " $n$ ". This indicates that stiffness of the ion gel can be controlled by adjusting an appropriate spacer length of the cross-linkable gemini-type IL. Furthermore, because the effect of the weak cross-linking of the silica nanoparticles was confirmed from the trend of the Young's moduli, it could be expected that the extensibility of the ion gel can be improved using the geminitype IL and nano components with well-designed shapes similar to the $\beta$-sheet nanocrystals in spider silk.

The superior toughness of the $\mu$-DN ion gel containing $\left[\mathrm{C}_{n}\left(\mathrm{C}_{2} \mathrm{OHim}\right)_{2}\right]\left[\mathrm{Tf}_{2} \mathrm{~N}\right]_{2}$ when compared to that of the other ion gels investigated in this research was strongly correlated with higher extensibility. The toughening mechanism of the DN gels is the energy dissipation due to the rupture of the sacrificial bond. Based on the energy dissipation mechanism, the toughness of inorganic/organic $\mu$-DN ion gels is dependent on the fractured amount of the silica particle network clusters because the silica particle network clusters played the role of the sacrificial bond in the $\mu$-DN ion gel. Therefore, increasing of the amount of the fractured silica particle network clusters should increase the dissipated energy. It can be easily understood that as the deformation of the ion gel increases, the amount of the silica particle network clusters in the deformed ion gel that is destroyed also increases. Because the $\left[\mathrm{C}_{9}\left(\mathrm{C}_{2} \mathrm{OHim}\right)_{2}\right]\left[\mathrm{Tf}_{2} \mathrm{~N}\right]_{2}-$ based $\mu$-DN ion gel withstood high deformation and remained intact, large numbers of silica particle network clusters were fractured when the $\mu$-DN ion gel was highly deformed. Thus, we conclude that the highly stretchable $\left[\mathrm{C}_{9}\left(\mathrm{C}_{2} \mathrm{OHim}\right)_{2}\right]\left[\mathrm{Tf}_{2} \mathrm{~N}\right]_{2^{-}}$ based $\mu$-DN ion gel showed excellent toughness.

\section{Conclusions}

In summary, the extensibility of the $\mu$-DN ion gels could be significantly improved using gemini-type ILs as the multiple $\mathrm{H}$ bond based weak cross-linker of the PDMAAm networks. Because the $\left[\mathrm{C}_{n}\left(\mathrm{C}_{2} \mathrm{OHim}\right)_{2}\right]\left[\mathrm{Tf}_{2} \mathrm{~N}\right]_{2}$-based $\mu$-DN ion gel withstood high deformation and remained intact, large numbers of silica particle network clusters were destructed under highly elongated state and dissipated the larger energy to give the $\mu$-DN ion gel excellent toughness. In addition, $\left[\mathrm{C}_{n}\left(\mathrm{C}_{2} \mathrm{OHim}\right)_{2}\right]\left[\mathrm{Tf}_{2} \mathrm{~N}\right]_{2}$ adsorbed on the surface of the silica nanoparticles could control the stiffness of the $\mu$-DN ion gels. From the results, it can be said that the multiple weak H-bonding strategy to crosslink the networks of the $\mu$-DN ion gels are useful to improve the mechanical strength, especially the extensibility and toughness, of the $\mu$-DN ion gels. Fine tuning of the inorganic component and polymer network as well as the gemini-type IL with weak $\mathrm{H}$ bonding ability could allow further increase in the mechanical strength of the ion gels; such an increase can enhance the opportunities for the practical applications of ion gels. 


\section{Conflicts of interest}

There are no conflicts to declare.

\section{Acknowledgements}

The silica nanoparticles (Aerosil 200) were supplied by Nippon Aerosil Co., Ltd. The authors thank the Research Facility Center for Science and Technology of Kobe University for the use of their FE-TEM. This research was financially supported by JSPSKAKENHI (Grant Number: 18K04812).

\section{Notes and references}

1 T. Ueki and M. Watanabe, Macromolecules, 2008, 41, 37393749.

2 A. Noda and M. Watanabe, Electrochim. Acta, 2000, 45, 12651270.

3 T. P. Lodge, Science, 2008, 321, 50-51.

4 J. E. Bara, E. S. Hatakeyama, D. L. Gin and R. D. Noble, Polym. Adv. Technol., 2008, 19, 1415-1420.

5 S. Kasahara, E. Kamio, A. Yoshizumi and H. Matsuyama, Chem. Commun., 2014, 50, 2996-2999.

6 F. Moghadam, E. Kamio, A. Yoshizumi and H. Matsuyama, Chem. Commun., 2015, 51, 13658-13661.

7 T. Yasui, E. Kamio and H. Matsuyama, Langmuir, 2018, 34, 10622-10633.

8 J. P. Gong, Y. Katsuyama, T. Kurokawa and Y. Osada, Adv. Mater., 2003, 15, 1155-1158.
9 E. Kamio, T. Yasui, Y. Iida, J. P. Gong and H. Matsuyama, Adv. Mater., 2017, 29, 1704118.

10 F. Ranjbaran, E. Kamio and H. Matsuyama, Ind. Eng. Chem. Res., 2017, 56, 12763-12772.

11 T. Giesa, M. Arslan, N. M. Pugno and M. J. Buehler, Nano Lett., 2011, 11, 5038-5046.

12 S. Keten, Z. Xu, B. Ihle and M. J. Buehler, Nat. Mater., 2010, 9, 359-367.

13 P. Song, Z. Xu and Q. Guo, ACS Macro Lett., 2013, 2, 11001104.

14 P. Song, Z. Xu, Y. Lu and Q. Guo, Macromolecules, 2015, 48, 3957-3964.

15 Z. S. Kean, J. L. Hawk, S. Lin, X. Zhao, R. P. Sijbesma and S. L. Craig, Adv. Mater., 2014, 26, 6013-6018.

16 K. Ueno, S. Imaizumi, K. Hata and M. Watanabe, Langmuir, 2009, 25, 825-831.

17 R. Tamate, K. Hashimoto, T. Horii, M. Hirasawa, X. Li, M. Shibayama and M. Watanabe, Adv. Mater., 2018, 30, 1802792.

18 R. S. Drago, N. O'Bryan and G. C. Vogel, J. Am. Chem. Soc., 1970, 92, 3924-3929.

19 Y. Wang and H. Morawetz, Macromolecules, 1989, 22, 164167.

20 T. Payagala, J. Huang, Z. S. Breitbach, P. S. Sharma and D. W. Armstrong, Chem. Mater., 2007, 19, 5848-5850.

21 S. A. Katsyuba, M. V. Vener, E. E. Zvereva, Z. Fei, R. Scopelliti, G. Laurenczy, N. Yan, E. Paunescu and P. J. Dyson, J. Phys. Chem. B, 2013, 117, 9094-9105. 